\title{
Isolated lingual involvement in Wilson's disease
}

\author{
Neera Choudhary, Laxmikant Joshi, Ashish Duggal, Vinod Puri, Geeta Anjum Khwaja \\ Department of Neurology, GB Pant Institute of Postgraduate Medicine and Research, Delhi, India
}

\begin{abstract}
Lingual involvement can occur in a variety of neurological disorders including pyramidal, extrapyramidal and lower motor neuron disorders. It can be seen in the form of tremor, bradykinesia, dystonia, atrophy and weakness of tongue movements and can clinically present as difficulty in swallowing and dysarthria which can be a source of great discomfort to the patient. We describe a patient who presented with isolated lingual involvement and was diagnosed to have Wilsons's disease. This case emphasizes the clinical variability in presentation of Wilson's disease and importance of early clinical diagnosis.
\end{abstract}

Key words: Bradykinesia, lingual involvement, Wilson's disease

\section{Introduction}

Wilson's disease is an autosomal recessive genetic disorder with variable neurological and hepatic manifestations. Lingual involvement in the form of dystonia, bradykinesia and tremor is rare but early neurological manifestation of Wilson's disease, which can often be missed or misdiagnosed. We report a patient who presented with isolated involvement of the tongue and was diagnosed to have Wilson's disease. It is important to be aware of this uncommon but important presentation as Wilson's disease is a potentially treatable condition and early diagnosis and treatment can be extremely gratifying.

\section{Case Report}

A 15-year-old male presented to us with 8 month history of progressive difficulty in swallowing and slurring of speech. Her mother had noticed that his

Videos on available at: www.ruralneuropractice.com

\begin{tabular}{|l|l|}
\hline \multicolumn{2}{|c|}{ Access this article online } \\
\hline Quick Response Code: & Website: \\
\hline & www.ruralneuropractice.com \\
\hline & \\
\hline
\end{tabular}

speech had become progressively unclear with words merging into each other, without any hoarseness or hyper nasality. He had difficulty in moving the morsel of food in the mouth and pushing it into back of throat but he was able to swallow both solids and liquids without any chocking or nasal regurgitation. The difficulty in swallowing and speech was constant without any fluctuations or diurnal variation. There was no history of tremulousnesss, motor weakness, sensory abnormalities or stiffness or slowing of activities of daily living. There was no history of any drug intake, fever, jaundice, joint pains or rashes. The patient was youngest of four siblings and there was no history of a similar illness in his family.

On examination, at the time of presentation, the patient was conscious and cooperative. Systemic examination was normal except mild splenomegaly. Neurological examination revealed normal higher mental functions but Myerson's sign was positive. A Kayser-Fleischer ring (KF ring) was present in both the eyes [Figure 1] and the cranial nerve examination (other than twelfth nerve) was normal. Tongue was normal in size without any evidence of atrophy or fasciculations but tone was increased on palpation [Video 1]. All the movements of tongue including protrusion and side to side lateral movements were limited; and tremors were noticed on limited protrusion of tongue. Motor, sensory and cerebellar examination were normal except for activated rigidity in the left upper limb at wrist joint and a reduced blink rate (10/minute). On the basis of history and clinical examination and presence of $\mathrm{K}-\mathrm{F}$ ring, a diagnosis of

\section{Address for correspondence:}

Dr. Neera Choudhary, Room No 503 Academic Block, G B Pant Institute of Post Graduate Medical Education and Research, Delhi - 110002 , India. E-mail: neerachudhary@gmail.com 
isolated tongue involvement as a result of Wilson's disease was entertained.

Hemogram revealed hemoglobin concentration of $12.7 \mathrm{gm} \%$. The whiteblood cell count was 3600 cells/cu.mm (neutrophil 50\%, lymphocytes 39\%, eosinophils $4 \%$ and monocytes $7 \%$ ) and platelets count was $88,000 / \mathrm{mm}^{3}$. The serum electrolytes and kidney function tests were normal. Serum bilirubin (total) was $0.6 \mathrm{mg} \%$ (direct fraction $0.2 \mathrm{mg}$ ) and serum proteins were $6 \mathrm{gm} \%$ (with a serum albumin of $3.4 \mathrm{gm} \%$ ), serum levels of AST, ALT and alkaline phosphatase were 45, 55 and $276 \mathrm{U} / \mathrm{L}$, respectively. His prothrombin and activated partial thromboplastin time were within normal limits. Serum ceruloplasmin was low with a value of $5 \mathrm{mg} / \mathrm{dL}$ (normal: 20-40 mg/dL), serum copper level was normal with a value of $82 \mu \mathrm{g} / \mathrm{dL}(63.7-140.12 \mu \mathrm{g} / \mathrm{dL})$ and 24 hour urinary copper was high with a value of $65 \mu \mathrm{g} /$ day $(<40 \mu \mathrm{g} /$ day). Ultrasound of abdomen revealed a reduced liver span $(11 \mathrm{~cm})$ with a nodular surface, splenomegaly and a portal vein diameter of $14 \mathrm{~mm}$, suggestive of cirrhosis and portal hypertension. MRI of brain revealed bilateral symmetrical hyperintensities in putamen, caudate, thalamus, midbrain and pons on T2-weighted images [Figure 2]. On the basis of K-F ring on examination, a low ceruloplasmin level, borderline raised 24-hour urinary copper and findings of chronic liver disease on ultrasound, a diagnosis of Wilson's disease with isolated lingual involvement. He was started on penicillamine with subsequent improvement in his speech and tongue movement [Video 2].

\section{Discussion}

Wilsons's disease is a rare autosomal-recessive disorder with a prevalence rate of 30 cases per million. The average age of symptom onset in persons who present with neurological dysfunction is 18.9 years although neurological symptoms may appear as early as 6 years. ${ }^{[1]}$

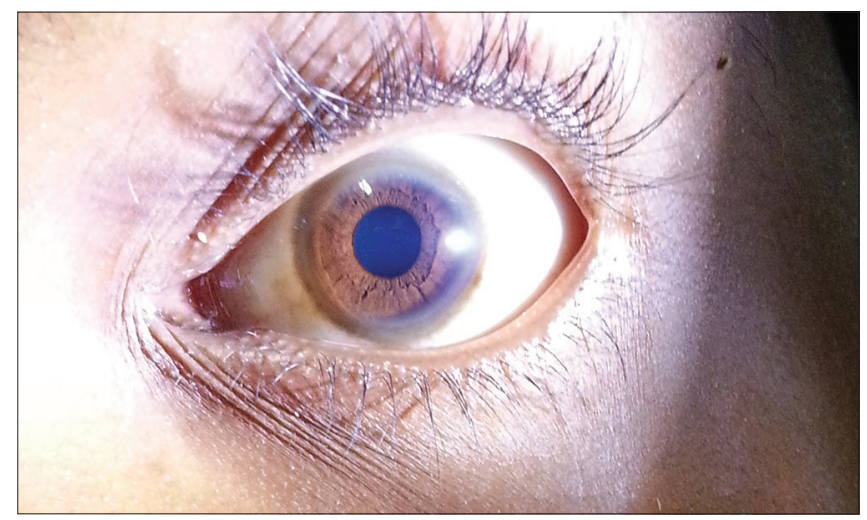

Figure 1: K-F ring visible on naked eye examination in patient with isolated lingual involvement due to Wilson's disease
The most common initial neurological manifestation of Wilson's disease is tremor, which may be resting, postural, or kinetic and predominantly involves the proximal upper extremity. Isolated lingual involvement is a rare manifestation of Wilson's disease and to the best of our knowledge only three cases have been reported in the past. ${ }^{[2-4]}$ Of these one patient had lingual dyskinesia, another had tremor of the tongue as an isolated finding and the third patient had lingual dystonia with abnormal protrusion of the tongue. Our patient had an increase in tone of the tongue with tremor and restriction of movements. Although our patient did not have any history suggestive of hepatic involvement or past history of jaundice, investigations revealed subclinical chronic liver disease with portal hypertension. Isolated tongue involvement can lead to drooling of saliva, dysarthria and difficulty in swallowing. It may not be an uncommon manifestation, but is often missed leading to a delay in diagnosis of Wilson's disease. Walshe et al. reported that in their series of 136 patients with a diagnosis of Wilson's disease, tongue involvement was the initial complaint in $17 \%$ of juveniles and $13 \%$ of adults, but was missed or misdiagnosed leading to a delay in diagnosis. ${ }^{[5]}$ Evaluation of a patient with lingual dystonia requires a complete history especially a detailed drug history since drugs such as first generation antipsychotic medications are the most common cause of lingual dystonia. Other causes of lingual dystonia could be trauma, electrical injury, infections or post encephalitic, secondary to heredodegenerative disorders and rarely primary lingual dystonia. In one of the largest series of lingual dystonia cases, Esper et al. reported that $41 \%$ of cases were secondary to medications, $18 \%$ heredodegenerative and post encephalitic, 12\% generalized dystonia and $29 \%$ focal primary lingual dystonia. ${ }^{[6]}$ Similarly, tremor of the tongue can be caused by parkinsonism, alcoholism and thyrotoxicosis. Restriction of movements of tongue can be seen in patients with Parkinson's

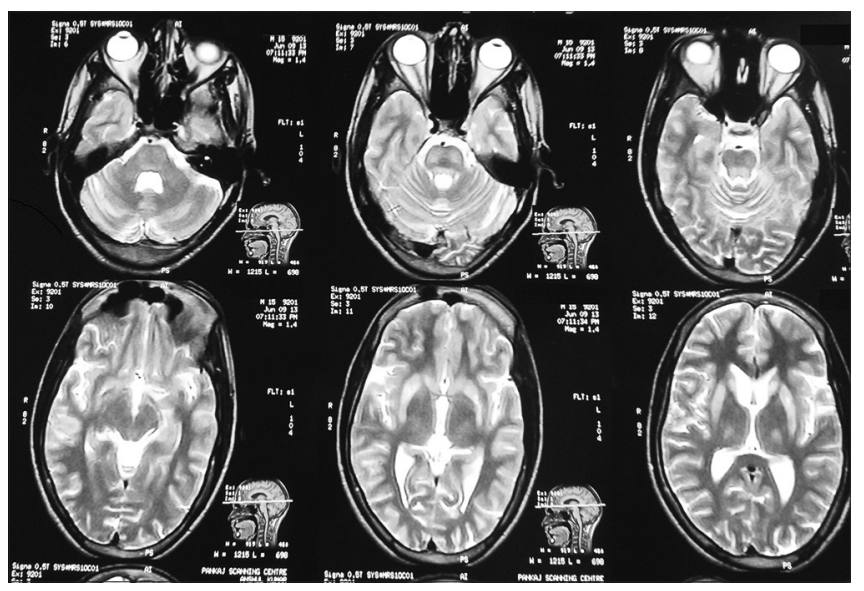

Figure 2: MRI of brain showing bilateral symmetrical hyperintensities in putamen, caudate, thalamus, on T2-weighted images 
disease, progressive supranuclear palsy, Wilson's disease, amyotrophic lateral sclerosis, medial Medulary syndrome, opercular syndrome and hypoglossal palsy. Among the neurodegenerative disorders affecting the tongue, Wilson's disease is particularly important because it is potentially treatable. So a slit lamp examination and serum ceruloplasmin levels should be evaluated in all patients, particularly young patients, who present with tongue involvement in the form of bradykinesia, tremor or dystonia.

To conclude, this case highlights one of the rare clinical manifestations of Wilson's disease. It is important to be aware of lingual involvement in Wilson's disease because it can commonly be missed and an early diagnosis can be extremely rewarding in this potentially treatable condition.

\section{References}

1. Pfeiffer RF. Wilsons's disease. Semin Neurol 2007;27:123-32.

2. Topaloglu H, Gücüyener K, Orkun C, Renda Y. Tremor of tongue and dysarthria as the sole manifestation of Wilsons's disease. Clin Neurol Neurosurg 1990;92:295-6.

3. Liao KK, Wang SJ, Kwan SY, Kong KW, Wu ZA. Tongue dyskinesia as an early manifestation of Wilson disease. Brain Dev 1991;13:451-3.

4. Kumar TS, Moses PD. Isolated tongue involvement-an unusual presentation of Wilsons's disease. J Postgrad Med 2005;51:337.

5. Walshe JM, Yealland M. Wilsons's disease: The problem of delayed diagnosis. J Neurol Neurosurg Psychiatry 1992;55:692-6.

6. Esper CD, Freeman A, Factor SA. Lingual protrusion dystonia: Frequency, etiology and botulinum toxin therapy. Parkinsonism Relat Disord 2010;16:438-41.

How to cite this article: Choudhary $N$, Joshi L, Duggal A, Puri V, Khwaja GA. Isolated lingual involvement in Wilson's disease. J Neurosci Rural Pract 2015;6:431-3.

Source of Support: Nil. Conflict of Interest: None declared. 